\title{
Investigating stratospheric changes between 2009 and 2018 with halogenated trace gas data from aircraft, AirCores, and a global model focusing on CFC-11
}

\author{
Johannes C. Laube ${ }^{1,2}$, Emma C. Leedham Elvidge ${ }^{2,3}$, Karina E. Adcock ${ }^{2}$, Bianca Baier ${ }^{4,5}$, \\ Carl A. M. Brenninkmeijer ${ }^{6}$, Huilin Chen ${ }^{7}$, Elise S. Droste ${ }^{2}$, Jens-Uwe Grooß ${ }^{1}$, Pauli Heikkinen ${ }^{8}$, Andrew J. Hind ${ }^{2}$, \\ Rigel Kivi ${ }^{8}$, Alexander Lojko ${ }^{2,9}$, Stephen A. Montzka ${ }^{5}$, David E. Oram ${ }^{2}$, Steve Randall ${ }^{10}$, Thomas Röckmann ${ }^{11}$, \\ William T. Sturges ${ }^{2}$, Colm Sweeney ${ }^{4}$, Max Thomas $^{2}$, Elinor Tuffnell ${ }^{2}$, and Felix Ploeger ${ }^{1,12}$ \\ ${ }^{1}$ Institute of Energy and Climate Research: Stratosphere, Jülich Research Centre, Jülich, 52428, Germany \\ ${ }^{2}$ School of Environmental Sciences, University of East Anglia, Norwich, NR4 7TJ, United Kingdom \\ ${ }^{3}$ Faculty of Science, University of East Anglia, Norwich Research Park, Norwich, NR4 7TJ, United Kingdom \\ ${ }^{4}$ Cooperative Institute for Research in Environmental Sciences, University of Colorado Boulder, Boulder, CO 80309, USA \\ ${ }^{5}$ Global Monitoring Division, National Oceanic and Atmospheric Administration, Boulder, CO 80305-3337, USA \\ ${ }^{6}$ Air Chemistry Division, Max Planck Institute for Chemistry, Mainz, 55128, Germany \\ ${ }^{7}$ Centre for Isotope Research, University of Groningen, Groningen, 9747 AG, the Netherlands \\ ${ }^{8}$ Space and Earth Observation Centre, Finnish Meteorological Institute, Sodankylä, 99600, Finland \\ ${ }^{9}$ Department of Climate and Space Sciences and Engineering, University of Michigan, Ann Arbor, MI 48109-2143, USA \\ ${ }^{10}$ Random Engineering Ltd., Felixstowe, IP11 9SL, United Kingdom \\ ${ }^{11}$ Institute for Marine and Atmospheric Research Utrecht, Utrecht University, Utrecht, 3508 TA, the Netherlands \\ ${ }^{12}$ Institute for Atmospheric and Environmental Research, University of Wuppertal, 42119 Wuppertal, Germany
}

Correspondence: Johannes C. Laube (j.laube@fz-juelich.de)

Received: 22 January 2020 - Discussion started: 14 February 2020

Revised: 13 June 2020 - Accepted: 16 July 2020 - Published: 20 August 2020

\begin{abstract}
We present new observations of trace gases in the stratosphere based on a cost-effective sampling technique that can access much higher altitudes than aircraft. The further development of this method now provides detection of species with abundances in the parts per trillion (ppt) range and below. We obtain mixing ratios for six gases (CFC-11, CFC-12, HCFC-22, H-1211, H-1301, and SF 6 ), all of which are important for understanding stratospheric ozone depletion and circulation. After demonstrating the quality of the data through comparisons with ground-based records and aircraft-based observations, we combine them with the latter to demonstrate its potential. We first compare the data with results from a global model driven by three widely used meteorological reanalyses. Secondly, we focus on CFC11 as recent evidence has indicated renewed atmospheric emissions of that species relevant on a global scale. Because the stratosphere represents the main sink region for
\end{abstract}

CFC-11, potential changes in stratospheric circulation and troposphere-stratosphere exchange fluxes have been identified as the largest source of uncertainty for the accurate quantification of such emissions. Our observations span over a decade (up until 2018) and therefore cover the period of the slowdown of CFC-11 global mixing ratio decreases measured at the Earth's surface. The spatial and temporal coverage of the observations is insufficient for a global quantitative analysis, but we do find some trends that are in contrast with expectations, indicating that the stratosphere may have contributed to the slower concentration decline in recent years. Further investigating the reanalysis-driven model data, we find that the dynamical changes in the stratosphere required to explain the apparent change in tropospheric CFC-11 emissions after 2013 are possible but with a very high uncertainty range. This is partly caused by the high variability of mass flux from the stratosphere to the troposphere, especially at 
timescales of a few years, and partly by large differences between runs driven by different reanalysis products, none of which agree with our observations well enough for such a quantitative analysis.

\section{Introduction}

Many halogenated trace gases are strong greenhouse gases and/or are involved in the ongoing depletion of the ozone layer; therefore, observations of these in the stratosphere are valuable. Moreover, measurements of some of these species allow us to constrain changes in stratospheric circulation and transport across the tropopause. An analytical challenge is posed by the low abundances of many such gases, in combination with the low ambient pressures found in this region of the atmosphere. Another challenge is the ability to reach the stratosphere as even the highest-flying research aircraft can only reach altitudes just above $20 \mathrm{~km}$ (Schauffler et al., 2003; von Hobe et al., 2013). This is modest considering that the stratosphere extends to around $50 \mathrm{~km}$. Large high-altitude balloons can reach altitudes of up to about $36 \mathrm{~km}$ (Engel et al., 2009; Ray et al., 2017), but due to the heavy payloads, they are increasingly difficult to fly given the risks for people living in landing areas and the cost or risk from lifting gases such as helium or hydrogen. Satellite (or aircraft) remote sensing plays an important role and can offer a global picture for some gases (Stiller et al., 2008; Santee et al., 2013; Harrison et al., 2019), but measurement precision and altitude resolution are often limited. They are also indirect observations and require continued validation through independent in situ methods. Generally, the mentioned platforms are rather expensive, ranging from costs of the order of EUR 10000 per flight hour for aircraft to satellite costs of millions of euros. The relatively recently developed AirCore technique (Karion et al., 2010), with flight costs of below EUR 2000 (depending on the setup), offers a cost-effective alternative. AirCores, which were named due to similarities to ice cores extracted from glaciers, are based on the concept of flying a very long lightweight coiled piece of stainless-steel tubing on a weather balloon. The tube is open on one end and therefore empties naturally upon ascent as ambient pressures decrease. During descent a full vertical profile of air is collected between the balloon's burst altitude (up to $36 \mathrm{~km}$ ) and ground level. This technology has been demonstrated before but for providing measurements of only a handful of higher abundance trace gases such as $\mathrm{CO}_{2}$ and $\mathrm{CH}_{4}$ (Karion et al., 2010; Membrive et al., 2017; Engel et al., 2017) and their isotopic composition (Mrozek et al., 2016; Paul et al., 2016).

However, due to the limited amount of air that is captured by AirCores, no ozone-depleting substances (ODSs) have been investigated yet, as their abundances are well below $1 \mathrm{ppb}$ (parts per billion). The importance of such observations is, however, demonstrated by the following example.
The recent work by Montzka et al. (2018) on renewed emissions of CFC-11 has received much attention since it indicates a substantial and ongoing breach of the global treaty designed to prevent the destruction of the stratospheric ozone layer: the Montreal Protocol on Substances that Deplete the Ozone Layer. According to their study, global CFC-11 emissions increased by $13 \pm 5 \mathrm{Gg} \mathrm{yr}^{-1}$ when comparing periods before and after 2012 with the caveat that up to $50 \%$ of that derived emission change might actually be attributable to changes in stratospheric processes or dynamics. More recently, Rigby et al. (2019) found similar global increases of $11-17 \mathrm{Gg} \mathrm{yr}^{-1}$ over $2014-2017$ vs. the $2008-2012$ average, and they also pinpointed a concurrent emissions increase source of $7.0 \pm 3.0 \mathrm{Gg} \mathrm{yr}^{-1}$ to eastern mainland China. However, they found no emission increases in other parts of the world covered by regular ground-based observations. This could mean that some of these emission increases have arisen in regions where no such measurements are available. An alternative explanation, i.e. the possibility of a sustained change to the amount of CFC-11 exchanged between the troposphere and the stratosphere as the driving mechanism for at least a part of the anomaly, has, however, not been ruled out so far.

\section{Methods}

Dry air mole fractions of halogenated trace gases were derived from air samples collected on board three different platforms: a passenger aircraft (CARIBIC; Brenninkmeijer et al., 2007) flying at altitudes of 8-13 km (11 flights, 20092016), a research aircraft (Leedham Elvidge et al., 2018) accessing higher altitudes of 9-21 km (M55 Geophysika, five campaigns, 2009-2017), and the first measurements of such gases with the relatively recently developed AirCore methodology (Karion et al., 2010; 8-30 km, 15 flights in Finland and the UK, 2016-2018). The aircraft data have partly been published before (Leedham Elvidge et al., 2018; Laube et al., 2013). The balloon-based AirCore technique was developed further, mainly through the use of specially designed tubing that maximises the amounts of air collected in the stratosphere, as well as through a novel subsampling technique that minimises the use of contamination-prone materials. The amount of retrievable stratospheric air, however, is still more than 2 orders of magnitude smaller than from aircraft-based sampling techniques. With laboratory analytical improvements compensating for this, the AirCore measurements show good precisions (ranging from $0.2 \%$ to $3.3 \%$ compared with $0.4 \%$ to $1.1 \%$ for aircraft samples) and excellent agreement with the aircraft data. The other important challenge for AirCore measurements of halocarbons is to ensure that the air is not contaminated throughout the entire sampling and subsampling process. Contaminations can arise from leakages and/or halocarbon-emitting materials (such as organic polymers) in the AirCore itself, in the $\mathrm{CO}_{2}$ analyser 

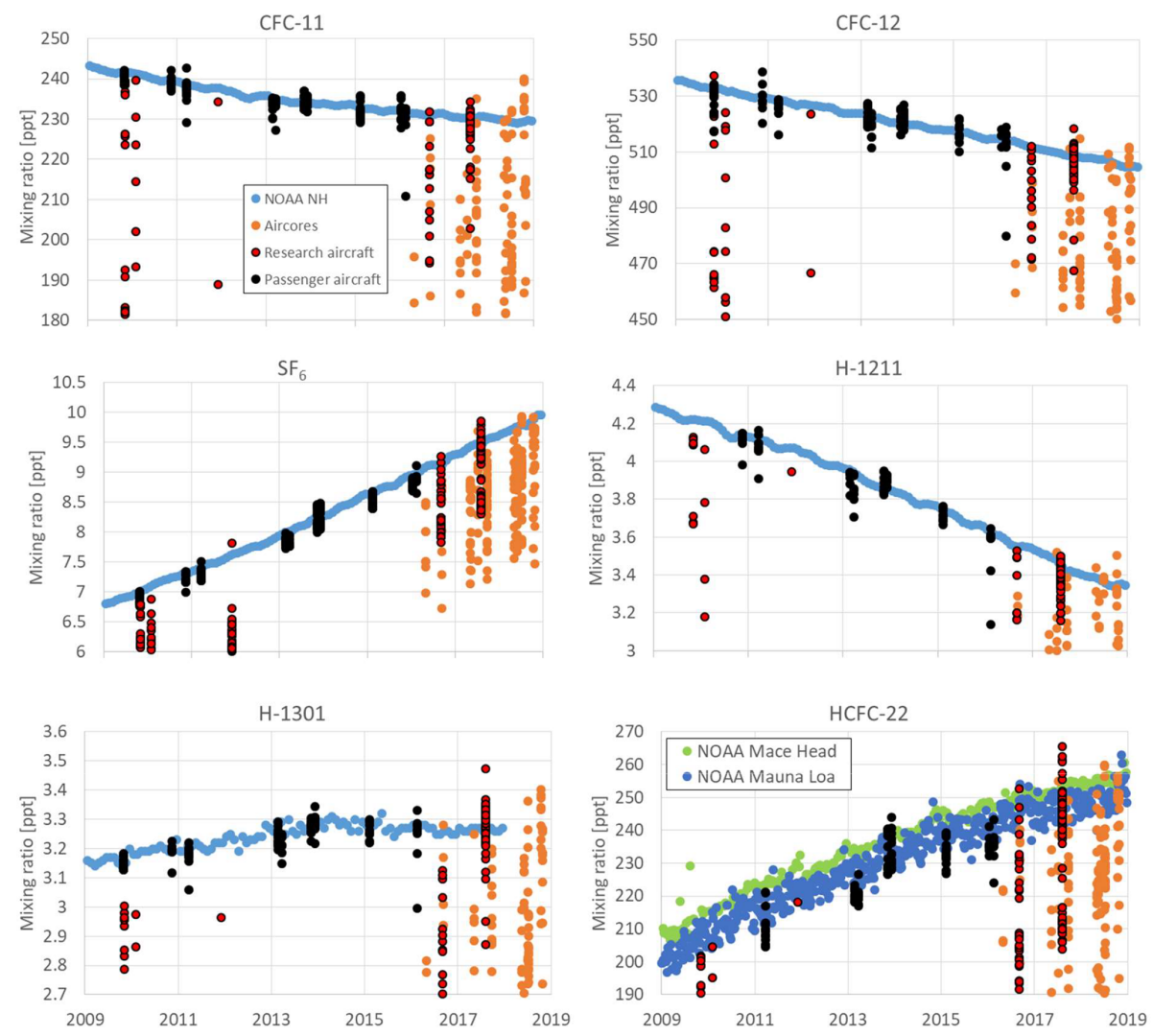

Figure 1. Aircraft- and balloon-based mixing ratios of six halogenated trace gases in the upper troposphere and stratosphere as compared to the NOAA/GMD ground-based northern hemispheric GGGRN time series (https://www.esrl.noaa.gov/gmd/, last access: 11 January 2020). HCFC-22 has a significant sink process in the troposphere and therefore exhibits stronger inner-hemispheric gradients. To illustrate that, we compare the mid-latitude station at Mace Head, Ireland, with the subtropical station at Mauna Loa, Hawaii. Lower mixing ratios generally represent higher altitudes. For all gases except $\mathrm{SF}_{6}$, some higher-altitude data are not shown to better demonstrate the good comparability of near-tropopause data to the NOAA time series. The complete corresponding data including uncertainties can be found in the Supplement (see also Figs. S1 to S4).

system including the pump, or in the subsampling system. Importantly, for all compounds reported here, mixing ratios in the stratosphere are much lower than in even remote tropospheric regions, let alone near sources of these gases. In addition, almost all of the contamination possibilities would affect the entire profile as an AirCore is essentially one air sample. This would become apparent in the correlations of the species with each other, which are very compact in the stratosphere. In the absence of such correlation breakdowns (see Figs. 1, 2, and S1 to S4), we therefore conclude that such contaminations are at undetectable levels in the dataset presented here. More details can be found in Table 1 and the Supplement.

All samples were processed with a previously described analytical system and methodology (Laube et al., 2010, 2012) using cryogenic extraction and pre-concentration, followed by gas chromatographic separation and detection with a high-sensitivity mass spectrometer. Trace gas measurements from this system as well as mean ages of air (AoAs, i.e. average stratospheric transit times; see section 3.1 for more details) calculated from these have been shown to compare very well with those of other internationally recognised measurements over several decades (Leedham Elvidge et al., 2018; Laube et al., 2013; Trudinger et al., 2016).

Stratospheric trends at AoA surfaces were derived by fitting second- and third-order polynomials (depending on whether an inflexion point was observed) to the respective correlations of mixing ratios and AoAs. The formulas of the polynomials were then used to interpolate onto the AoA surfaces $(1,2,3$, and/or 4 years, depending on which AoA range was covered) for each flight. To test the uncertainty of this method, the data for each flight were first replicated four times, where each replicate was modified by plus or minus the uncertainty in the mixing ratio and mean age uncertainties. This resulted, for each data point, in the average plus minimum and maximum value for both mixing ratio and AoA. Subsequently, $5 n$ ( $n$ being the number of data points available for each flight) random samples were drawn (repeat draws possible) with a bootstrap algorithm (as in Volk et al., 1997; Laube et al., 2013), and a second- or third-order poly- 
nomial again fitted. This procedure was repeated 500 times for each flight, resulting in an average mixing ratio and an uncertainty range at each AoA surface. The derived mixing ratios were subsequently used to produce linear regressions over time, including a weighting by the inverse uncertainties of the individual CFC (chlorofluorocarbon) mixing ratios. The bootstrapping algorithm (500 repeat draws, repeat draws possible) was used again to ensure that the derived slope uncertainties were not underestimated and that individual high or low points did not bias the slope estimates.

Observation-based data were compared to model output from the Chemical Lagrangian Model of the Stratosphere (CLaMS), a Lagrangian chemical transport model with advective transport calculated from three-dimensional forward trajectories and an additional parameterisation for smallscale turbulent mixing (McKenna et al., 2002). Potential temperature is used as vertical coordinate throughout the stratosphere with vertical velocity estimated from the total diabatic heating rate. Further model details and the chemistry scheme used are described in Pommrich et al. (2014). For the simulations used in this study, CLaMS was driven with horizontal winds and diabatic heating rates from three alternative meteorological reanalysis datasets: ERA-Interim (from the European Centre for Medium-Range Weather Forecasts, ECMWF), JRA-55 (from the Japan Meteorological Agency), and MERRA-2 (from NASA). For more information on methods, calibrations, and modelling, as well as additional data, please see the Supplement.

\section{Results and discussion}

\subsection{Observational data overview and comparisons}

Our data are based on measurements of air samples collected in the upper troposphere and stratosphere of the northern hemisphere using aircraft and weather balloons between 2009 and 2018. Figure 1 shows the obtained mixing ratios alongside the northern hemispheric "background" time series derived through the combination of observations at various ground-based stations within the National Oceanic and Atmospheric Administration Global Monitoring Division's Global Greenhouse Gas Reference Network (NOAA/GMD GGGRN). It is apparent that both the aircraft and the balloon data follow the ground-based trends quite well for all six gases. Slightly enhanced mixing ratios can often be observed in the vicinity of the tropopause (see also Figs. S5 and S6), mostly due to recent influences from regional emissions (Kloss et al., 2014; Leedham Elvidge et al., 2015; Oram et al., 2017). This is especially pronounced in the research aircraft data from 2017, which belong to a campaign (Höpfner et al., 2019) exploring the atmospheric composition above the polluted Asian monsoon region (Randel et al., 2010; Vogel et al., 2019). It is, however, worth noting that most species' enhancements are not significantly higher than the
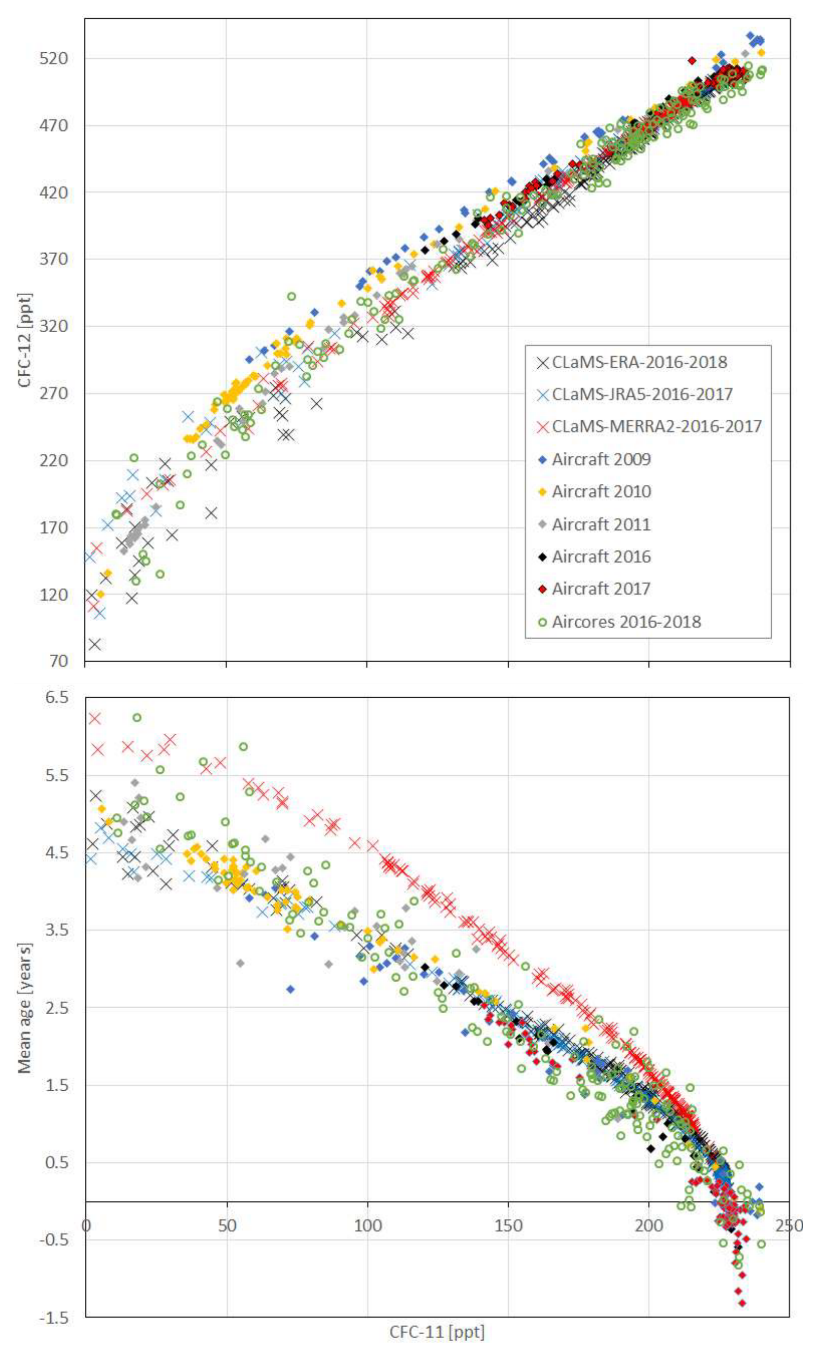

Figure 2. Stratospheric CFC-12 mixing ratios and the mean age of air (AoA) as a function of CFC-11 mixing ratios, as observed in air samples collected by research aircraft (diamonds) and AirCore samples (circles). Crosses denote the values obtained from the CLaMS model sampled at the same times and coordinates as the observations but, for better visibility, only from 2016 onwards. The CLaMS model was run using three different meteorological reanalysis packages: ERA-Interim (black), JRA-55 (blue), and MERRA-2 (red).

combined measurement uncertainties, which demonstrates the importance of the consistency of the datasets and therefore the quality of the stratospheric record. Figure 1 also illustrates the much improved temporal density that AirCore observations have provided from 2016 onwards (in comparison to aircraft campaigns), especially at altitudes above $15 \mathrm{~km}$, which are out of the reach of all but a few research aircraft.

In the stratosphere, trace gases typically exhibit compact interspecies correlations (Schauffler et al., 2003; Volk et al., 1997), and some gases (such as $\mathrm{SF}_{6}$ ) can be utilised to de- 

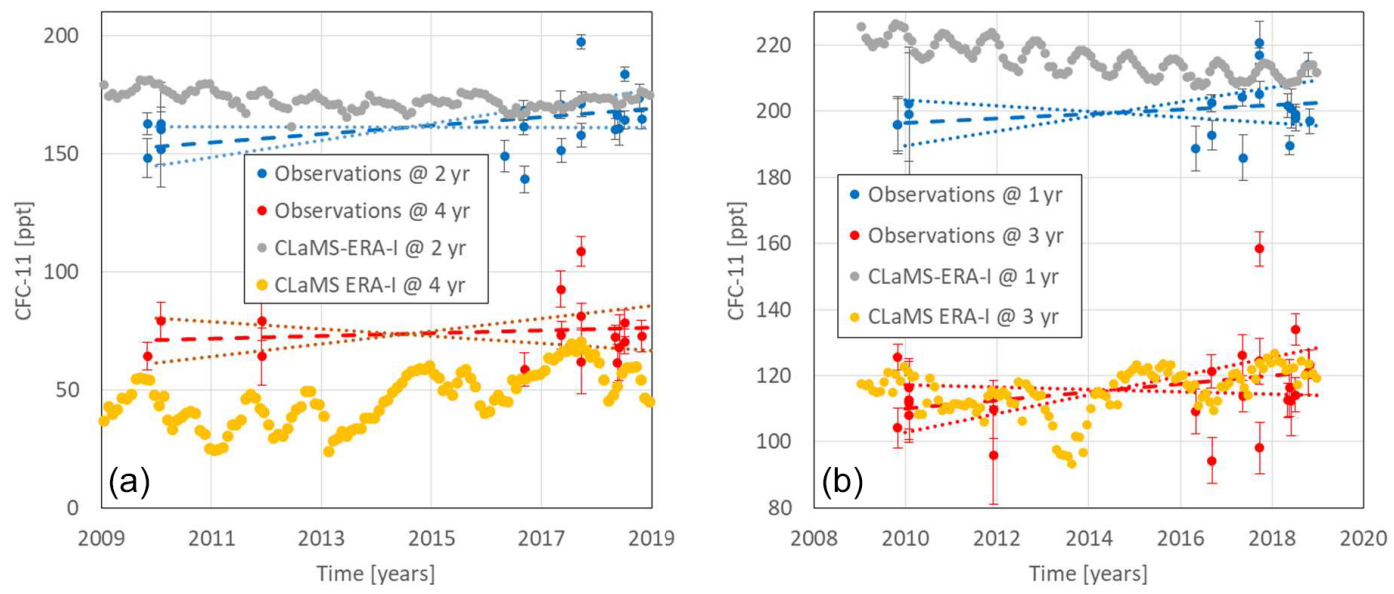

Figure 3. Panel (a) shows a comparison of observation-based CFC-11 mixing ratio trends at mean ages of air of 2 (blue), and 4 (red) years with those from the CLaMS model run driven by the ERA-Interim reanalysis (grey and yellow) in the northern hemispheric stratosphere. The latter have been derived as averages between 30 and $90^{\circ} \mathrm{N}$. The dashed and dotted lines correspond to regression lines (weighted by their $1 \sigma$ standard error for observations) and an illustration of their $2 \sigma$ uncertainties over the time periods displayed. Panel (b) shows the same comparison but at mean ages of 1 and 3 years. The numerical values can be found in Table 2 .

rive average stratospheric transit times, which are more commonly known as mean ages of air (AoAs; Engel et al., 2009; Ray et al., 2017; Stiller et al., 2008; Leedham Elvidge et al., 2018). The correlations between CFC-11 and CFC-12 as well as between CFC-11 and AoA derived from observations (see Supplement Sect. S1.2 for details) are shown in Fig. 2. Two things are apparent. Firstly, this again demonstrates the consistency and quality of our data as similar correlations are observed for both aircraft- and AirCore-based mixing ratios over the entire range. Secondly, the correlations have not undergone a large shift in the last 10 years. Correlations between trace gases are often driven by changes in tropospheric trends, as tropospheric air keeps "feeding" the stratosphere. A large shift in these correlations would therefore not be expected as both CFC-11 and CFC-12 have experienced relatively small negative tropospheric trends in recent years (Montzka et al., 2018; Rigby et al., 2019). However, there are other factors that can change the correlations, namely changes in stratospheric chemistry and transport. The CFC11-AoA correlation in particular would be affected if, for example, the main transport pathways and or times (AoAs) inside the stratosphere had changed. This possibility is investigated further below.

\subsection{Comparisons with model data using different reanalyses}

We first focus on a comparison of model simulations with the aircraft and AirCore data. Also shown in Fig. 2 are data from simulations with the Chemical Lagrangian Model of the Stratosphere (CLaMS; McKenna et al., 2002; Pommrich et al., 2014). The latter was driven alternatively by three commonly used meteorological reanalyses, i.e. ERA-Interim, JRA-55, and MERRA-2 (Dee et al., 2011; Kobayashi et al.,
2015; Gelaro et al., 2017). These newest available meteorological reanalysis datasets provide the best guess of the current state of the atmosphere. We use the differences between them to quantify the uncertainty in our knowledge of the stratospheric circulation and its changes. The model was sampled at coordinates and times coinciding with those of the observations. Results from all three runs are similar to those from observations in the case of the correlation of CFC-11 with CFC-12. The CFC-11-AoA correlation in Fig. 2 is a measure of the speed of the main stratospheric overturning circulation as it reflects, in an integrated way, the speed and pathway of trace gas transport through the stratosphere. Here, the model data for both ERA-Interim and JRA55 remain close to the observed values throughout the range. The MERRA-2-based data does, however, stand out producing higher AoAs at similar stratospheric CFC-11 mixing ratios and an increasing discrepancy with increasing AoA. As noted by Ploeger et al. (2019), the MERRA-2 reanalysis has a slower stratospheric circulation, and our observational evidence strongly indicates that it is indeed too slow. This is a consistent feature, which is also apparent when comparing with MERRA-2-based data from before 2016 (not shown in Fig. 2). The details of the causing mechanisms could be complex and are beyond the scope of this work.

\subsection{Long-term trends of trace gases in the stratosphere}

Focusing on the details of the correlations in Fig. 2, we investigate whether there are indications here that might partly explain the recent changes in the tropospheric trend of CFC11. Most air enters the stratosphere in the tropics and is then transported poleward. CFC-11 and CFC-12 molecules are mostly destroyed in the tropical stratosphere (Douglass et al., 2008). Transport of the remainder of these gases to the 
Table 1. Comparison of average measurement uncertainties (derived as the average of 1 standard deviation from repeated working standard or air sample measurements) of the research aircraft campaign in 2016; all AirCore flights; and some AirCore sample repeats for CFC-11, CFC-12, H-1211, H-1301, HCFC-22, and SF 6 . For AirCore uncertainties, the average working standard uncertainty over 3 years was used as it is (a) more representative of the entire measurement period and (b) generally comparable or worse than precisions derived from sample repeats. AirCore-based precisions are generally slightly worse than those achieved with the larger aircraft-based samples but still much smaller than mixing ratio gradients observed in the stratosphere.

\begin{tabular}{lrrr}
\hline Trace gas & $\begin{array}{r}\text { Average precision (\%) } \\
\text { of aircraft 2016 measurements }\end{array}$ & $\begin{array}{r}\text { Average precision (\%) } \\
\text { of AirCore 2016-2018 } \\
\text { standards }\end{array}$ & $\begin{array}{r}\text { Average precision }(\%) \\
\text { of AirCore 2017 } \\
\text { sample repeats }\end{array}$ \\
\hline $\mathrm{CFC}-11\left(\mathrm{CFCl}_{3}\right)$ & 0.4 & 0.9 & 1.2 \\
$\mathrm{CFC}-12\left(\mathrm{CF}_{2} \mathrm{Cl}_{2}\right)$ & 1.1 & 1.2 & 0.8 \\
$\mathrm{H}-1211\left(\mathrm{CF}_{2} \mathrm{ClBr}\right)$ & 0.6 & 1.9 & 1.0 \\
$\mathrm{H}-1301\left(\mathrm{CF}_{3} \mathrm{Br}\right)$ & 0.6 & 3.3 & 2.3 \\
$\mathrm{HCFC}-22\left(\mathrm{CHF}_{2} \mathrm{Cl}\right)$ & 0.6 & 0.9 & 0.2 \\
$\mathrm{SF}_{6}$ & 0.4 & 0.9 & 0.6 \\
\hline
\end{tabular}

poles is much slower than in the troposphere and takes several years (Kida, 1983; Schmidt and Khedim, 1991) as is reflected in the CFC-11-AoA correlation in Fig. 2. In the case of an acceleration of parts of the circulation, for which there have been observational indications (Bönisch et al., 2011; Stiller et al., 2012), that correlation should therefore shift. We consequently fitted the CFC-11-AoA correlation with a second- or third-order polynomial for each individual research aircraft and balloon flight and calculated the mixing ratio of CFC-11 after having spent, on average, 1, 2, 3, and 4 years in the stratosphere. Figure 3 shows examples of the trends at the four residence times from 2009 to 2018, and the full data can be found in the Supplement.

While there is substantial variability of mixing ratios at these AoA surfaces over time, we do find a positive trend (increases from 3\% to 10\%) from 2009 to 2018 for all observation-based (aircraft and AirCore) estimates. The trends at an AoA of 1 and 4 years are not significantly positive, but the ones at 2 and 3 years are, within 2.0 and 1.6 standard deviations of the slope uncertainties, respectively (Fig. 3, Table 2). These stratospheric trends contrast the tropospheric trend of CFC-11, which has been negative throughout that period ( $\sim-6 \%$ in total, Fig. 1). While there is a certain lag time for air to reach our stratospheric observation points (i.e. 1, 2, 3, and 4 years on average), CFC-11 had been decreasing nearly linearly in the troposphere since the late 1990s. In turn this implies that changes in stratospheric circulation may indeed have played a substantial role in the recent changes to the tropospheric trend of CFC-11 as previously suspected (Montzka et al., 2018). The causes are not explicable with an integrated quantity such as AoA as the underlying distribution of stratospheric transit times cannot currently be inferred from trace gas observations. However, it should be noted that the limited temporal and spatial coverage of the observation-based measurements and especially the gap between 2011 and 2016 represents an additional and unquantifiable source of uncertainty.
For the other three gases that have sufficient measurement precisions for such an analysis (i.e. CFC-12, H-1211, and HCFC-22), we also find a picture that does not agree well with their tropospheric trends (Table 2). Both CFC-12 and $\mathrm{H}-1211$ have been in decline in the troposphere since the mid-2000s and decreased by $\sim 6 \%$ and $\sim 20 \%$ between late 2009 and late 2018, respectively (Fig. 1), whereas tropospheric HCFC-22 mixing ratios have increased monotonically (and by $\sim 25 \%$ during our observation period) since the trace gas appeared in the atmosphere several decades ago, albeit with a recent slowdown. In contrast, in the stratosphere, we find that CFC-12 decreased at all mean age surfaces but not as much as in the troposphere $(-0.9 \%$ to $-4 \%)$; HCFC-22 increased disproportionally by $30 \%$ to $38 \%$; and $\mathrm{H}-1211$ decreased, but only at a mean age of 1 year $(-9 \%)$. No significant change occurred at 2 years, and $9 \%$ to $22 \%$ increases were observed at 3 and 4 years. For the latter three gases, this unexpected behaviour could be partly related to changes in tropospheric trends in the period leading up to 2009 , as a significant part of the air at certain mean age levels is much older than the mean age itself. However, these effects should subside over the decade that our observations span, especially for H-1211, which is the shortest-lived gas of the four. In addition, CFC-11 should not be affected as it has been decreasing for much longer. The underlying mechanisms are likely complex.

The only straight-forward possibility to generate positive CFC-11 trends in the stratosphere between 2009 and 2018 would be an increase in the air fractions that have younger and older residence times than the inferred mean age. Such a 2-fold increase would maintain the same AoA, but would influence the mixing ratios observed at the AoA surfaces in different ways. If the increased older air fraction had been in the stratosphere for long enough, it would have already lost virtually all of its content of shorter-lived gases (H1211 and CFC-11). However, if this older air fraction at the same time would be in an AoA range where the longer-lived 
Table 2. Temporal trends and their $2 \sigma$ uncertainties of CFC-11, CFC-12, HCFC-22, and H-1211 mixing ratios at AoAs of 1, 2, 3, and 4 years. These slopes correspond to an uncertainty-weighted regression line fitted to the data in Figs. 3, and S8-S12, with two exceptions: (1) the data from the Asian monsoon campaign in 2017 was excluded as this region is not representative of northern hemispheric stratospheric air and (2) all data at mean ages above 3.5 years from winter campaigns in high latitudes were also excluded as they might contain polar vortex air, which is equally unrepresentative. Model-based slopes were derived over the same period as observational data (August 2009-August 2018), except for JRA-55 and MERRA-2, where data were only available until the end of 2017.

\begin{tabular}{|c|c|c|c|c|}
\hline CFC-11 & 1 year & 2 years & 3 years & 4 years \\
\hline Slope obs. (ppt yr ${ }^{-1}$ ) & 0.69 & 1.77 & 1.25 & 0.59 \\
\hline Uncertainty (ppt yr $\left.{ }^{-1}\right)$ & 1.54 & 1.81 & 1.60 & 2.12 \\
\hline Trend ( $\%$ per decade) & 3.2 & 10.4 & 10.2 & 7.4 \\
\hline Slope ERA-Interim & -1.35 & -0.50 & 1.15 & 3.09 \\
\hline Uncertainty & 0.22 & 0.24 & 0.47 & 0.61 \\
\hline Slope JRA-55 & -1.56 & -1.38 & -0.08 & 1.73 \\
\hline Uncertainty & 0.21 & 0.20 & 0.27 & 0.62 \\
\hline Slope MERRA-2 & -1.69 & -1.51 & -1.20 & -0.55 \\
\hline Uncertainty & 0.18 & 0.23 & 0.23 & 0.30 \\
\hline \multicolumn{5}{|l|}{ CFC-12 } \\
\hline Slope obs. (ppt yr ${ }^{-1}$ ) & -1.96 & -0.45 & -0.38 & -1.33 \\
\hline Uncertainty (ppt yr ${ }^{-1}$ ) & 1.90 & 2.20 & 2.52 & 5.36 \\
\hline Trend (\% per decade) & -3.6 & -0.95 & -0.93 & -3.9 \\
\hline Slope ERA-Interim & -3.09 & -2.52 & -1.52 & 3.21 \\
\hline Uncertainty & 0.37 & 0.48 & 0.62 & 1.20 \\
\hline Slope JRA-55 & -3.17 & -3.09 & -1.37 & 2.39 \\
\hline Uncertainty & 0.28 & 0.41 & 0.60 & 1.08 \\
\hline Slope MERRA-2 & -3.26 & -3.17 & -3.02 & -2.40 \\
\hline Uncertainty & 0.24 & 0.39 & 0.51 & 0.76 \\
\hline \multicolumn{5}{|l|}{ HCFC-22 } \\
\hline Slope obs. (ppt yr ${ }^{-1}$ ) & 6.15 & 6.16 & 5.98 & 5.67 \\
\hline Uncertainty (ppt yr ${ }^{-1}$ ) & 0.15 & 0.14 & 0.14 & 0.18 \\
\hline Trend (\% per decade) & 30.5 & 33.4 & 36.0 & 38.2 \\
\hline \multicolumn{5}{|l|}{ H-1211 } \\
\hline Slope obs. (ppt yr $\left.{ }^{-1}\right)$ & -0.031 & 0.000 & 0.013 & 0.013 \\
\hline Uncertainty $\left(\mathrm{ppt} \mathrm{yr}^{-1}\right.$ ) & 0.008 & 0.008 & 0.007 & 0.009 \\
\hline Trend ( $\%$ per decade) & -9.0 & 0.2 & 9.1 & 22.4 \\
\hline
\end{tabular}

gases (CFC-12 and HCFC-22) are still present in significant amounts, then an increase in its share should lead to a decrease in CFC-12 and HCFC-22 mixing ratios (but less so for the latter as it is much longer lived in the stratosphere). To balance this increase in the older air fraction and maintain a constant mean age, the younger fraction of the AoA spectrum would also need to have an increased share. Younger air generally contains higher mixing ratios of all four gases - and disproportionally so for HCFC-22 as its tropospheric mixing ratios continue to increase. If the increases in the two fractions of the AoA spectrum would be in the right AoA range, the overall effect would then be an increase of mix- ing ratios of CFC-11, H-1211, and HCFC-22 over time at a given AoA surface, accompanied by a decrease in CFC-12 mixing ratios. This would then be entirely consistent with the changes we observed at almost all AoA levels between 2009 and 2018. Therefore, such a change to the stratospheric transit time distributions could be considered the simplest case that would qualitatively explain our observations.

The aforementioned possibility to at least partly explain such trends could include an acceleration of air mass transport through the lower tropical stratosphere (i.e. below the main sink region of CFC-11) as, for example, CLaMSERA-Interim qualitatively shows over the relevant period (Fig. S15). However, when compared with ERA-Interimbased model data at the same transport times (Fig. 3), the model results show a different CFC-11 trend in the lower stratosphere. In fact, the model- and observation-based trends at mean ages of 1 and 2 years do not agree within 2 standard deviations. This discrepancy is likely related to a known problem with ERA-Interim, which generally overestimates the speed of the circulation in that lower stratospheric region (Dee et al., 2011; Ploeger et al., 2012). At larger mean ages, we find better agreement between the observations and the model with the model data even reproducing the observed insignificant trend. JRA-55-based model trends are very similar to those from the ERA-Interim-based analysis, whereas the MERRA-2 reanalysis shows larger differences to observations, both in terms of mixing ratios and trends (Table 2, Figs. 3, and S8-S12). The generally limited comparability of model and observations sheds some light on the ability of current reanalysis products to quantify structural changes in stratospheric circulation patterns.

\subsection{Mass flux estimates of CFC-11}

Nevertheless, we use the reanalysis-driven model data as the best available means to derive the downward mass flux of CFC-11 through the extratropical tropopause, i.e. the quantity describing how much CFC-11 is transported back to the troposphere. Comparing the three simulations driven with three different reanalyses provides an estimate of uncertainty due to representations of stratospheric circulation changes. A temporal increase of the stratosphere-to-troposphere mass flux could cause changes to the tropospheric trend of CFC11, which would look like renewed emissions. Such a flux increase could be consistent with the observed increases in CFC-11 mixing ratios on AoA surfaces (Sect. 3.3) if accompanied by an increased fraction of air entering the stratosphere without passing through the main CFC-11 sink region in the lower tropical stratosphere (and instead entering, for example, through the Asian summer monsoon).

The NOAA/GMD tropospheric time series of CFC-11 serves as the boundary condition for the model, and consequently in the absence of stratospheric changes, the temporal trend of the mass flux should be similarly negative and of a similar magnitude. The model generally reflects this reason- 
ing over longer time periods as can be seen in Fig. 4. We then follow the approach by Montzka et al. (2018) to investigate whether the changes to the tropospheric trend around 2013 might partly be caused by more CFC-11 being transported back into the troposphere. For that purpose, we split the data into two periods: before and after 2013. Independent of which definition of the tropopause is being used (see the Supplement for details), we find an increase in the mass flux of around $37 \mathrm{Gg} \mathrm{yr}^{-1}$ after 2013 for CLaMS-ERA-Interim. This would explain $270 \%$ of the observed slowdown of CFC11 mixing ratio decreases after 2013 when comparing to the $13 \pm 5 \mathrm{Gg} \mathrm{yr}^{-1}$ emission increase inferred by Montzka et al. (2018). At first glance, this very high stratospheric contribution is not consistent with the findings of both Montzka et al. (2018) and Rigby et al. (2019), who estimated $40 \%$ to $60 \%$ of the slowdown to belong to renewed emissions. However, the global stratosphere-to-troposphere mass flux is very large compared to the amount of unexplained emissions, and a direct quantitative comparison is not possible, as explained in the following. When repeating the same model run, but with an artificial tropospheric CFC-11 trend that continues to decrease linearly after 2013 the mass flux remains very similar to the reference simulation (difference of $\left.<0.6 \mathrm{Gg} \mathrm{yr}^{-1}\right)$. This translates into a minor influence of recent tropospheric trend changes on these stratospheric fluxes and therefore confirming that this signal is indeed driven by stratospheric changes in the ERA-Interim world. However, this pronounced turnaround in 2013 is not a consistent feature for all three reanalyses, as the JRA-55 run, despite producing such a similar picture in the correlation comparisons (Fig. 2), in fact shows a further decrease of $0.4 \mathrm{Gg} \mathrm{yr}^{-1}$ (equivalent to $-3 \%$ of the new emissions signal) after 2013 . The main reason for that discrepancy is that, as opposed to ERA-Interim, JRA-55 does not show a substantial change to the mass flux around 2013. Coming back to the pre- and post2013 analysis, CLaMS-MERRA-2 results are in between the other two with $18.2 \mathrm{Gg} \mathrm{yr}^{-1}$ (135\%), but have the least credibility as demonstrated by the poor comparability with observations. The main issue connected with such an analysis is illustrated in Fig. 4. With annual changes of up to $21 \%$, the variability of the CFC-11 mass flux from the stratosphere to the troposphere is an order of magnitude higher than the 2013 change of $2 \%$ to $5 \%$ that we are trying to quantify. Some of that mass flux variability occurs over several years, which severely limits the capability of quantitatively determining trend changes between an 11- and a 5-year period. It should, however, be re-emphasised that a mass flux trend analysis over longer periods would be expected to work better and this is indeed what we find for ERA-Interim and JRA-55. Between 2002 and 2017 the CFC-11 flux from a linear regression of the model output driven by these two reanalyses decreases by $10.5 \%$ and $13.1 \%$, respectively, which is comparable to the $\sim 11 \%$ tropospheric decrease over the same period. MERRA-2 again produces an outlier with only a $3.2 \%$ decrease during those 16 years. The recent findings by Ray

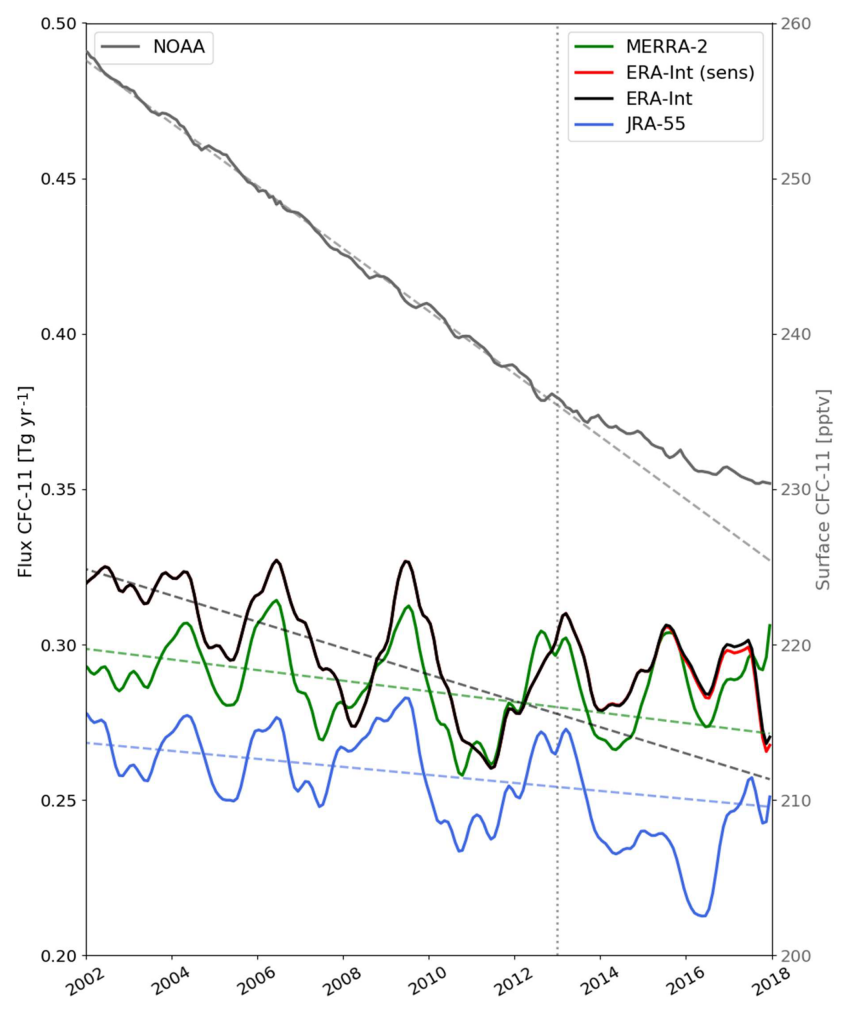

Figure 4. The annually averaged stratosphere-to-troposphere mass flux of CFC-11 through the tropopause between 2002 and 2018 for CLaMS model runs driven by MERRA-2 (green), JRA-55 (blue) and ERA-Interim (black) reanalyses including a linear regression for the period until 2013 (dashed). The red line originates from an ERA-Interim sensitivity run for which tropospheric CFC-11 was forced to continue to decrease at the same rate as before 2013 . Shown in grey and on the right-hand y axis are the two corresponding time series of tropospheric CFC-11 mixing ratios (i.e. the real one, solid, and the one with the forced decrease, dashed). The annual average has been calculated by applying a 12-month running mean to the time series.

et al. (2020) of the QBO (Quasi-biennial Oscillation) significantly modulating the variability of long-lived trace gases at the surface are qualitatively consistent with our findings for both shorter and longer periods. However, a quantification of this modulation is currently limited by the uncertainties connected to the meteorological reanalyses in the stratosphere. As shown in Fig. 4, the mass fluxes from the three CLaMSreanalysis runs show some covariation on QBO timescales but at the same time also some significant differences which include offsets, long-term trends, the magnitude of the variations, and the timing of changes.

\section{Conclusions}

To summarise, we present new observations of six halogenated trace gases in the stratosphere obtained from applying a further-developed AirCore technology. These ob- 
servations are consistent with ground-based measurements of the same species at remote locations. They compare well to aircraft-based observations, have good precisions, and offer a viable low-cost method for directly observing ozonedepleting gases and circulation tracers in the stratosphere at enhanced temporal and spatial resolutions. The derived mixing ratios and mean stratospheric residence times, both from aircraft and AirCore data, enable the assessment of the performance of the three most modern currently available meteorological reanalysis packages. The ERA-Interim- and JRA55-derived model data compare better, whereas the MERRA2-based data exhibit distinctly slower transport through most of the region covered here.

From a further analysis of the observational data at certain stratospheric transport times, we also find insignificant to positive trends (within 1 standard deviation) of CFC-11 mixing ratios in the lower stratosphere between 2009 and 2018 ranging from $3 \%$ to $10 \%$. This is surprising and in contrast to expectation from the tropospheric abundances, which have been decreasing by about $6 \%$ over that period. Similarly derived trends for CFC-12, HCFC-22, and H-1211 are also not in good agreement with their corresponding tropospheric trends. In a qualitative sense, and keeping in mind the regional nature of these measurements and the uncertainties related to the calculation of stratospheric transport times, this would point towards increasing mass fluxes of CFC-11 being transported back to the troposphere. Our observations therefore do support the hypothesis of new emissions being lower than expected from tropospheric trends alone. More generally, there is evidence for a significant and time-dependent role of the stratosphere in the modulation of tropospheric trends of trace gases. However, any further quantification of the stratospheric part of the CFC-11 story is prevented firstly by the non-global and intermittent nature of sufficiently precise observations as well as their limited comparability to model or reanalysis results; secondly by the variability of the CFC-11 stratosphere-to-troposphere mass flux influenced by, for example, QBO, ENSO (El Niño-Southern Oscillation), volcanic eruptions, and also stratospheric transport changes as indicated by the observed trace gas trends on AoA surfaces; and thirdly by the large differences between results from different current meteorological reanalyses. The quality of the latter is currently the main limitation to refining such calculations.

Finally, our observations span 10 years, which is a short time in comparison to the long-term climate-change-driven stratospheric circulation changes expected from global models, which are of the order of decades (Polvani et al., 2018). Our data, however, demonstrate the capabilities of the AirCore observations to increase data coverage and better constrain such changes on various timescales.
Data availability. Observational data are included in the Supplement, and the CLaMS model data may be requested from the corresponding author.

Supplement. The supplement related to this article is available online at: https://doi.org/10.5194/acp-20-9771-2020-supplement.

Author contributions. JCL conducted the analysis of the overall dataset, participated in several campaigns, carried out some of the measurements, and led the writing of the article. ECLE, BB, HC, ESD, PH, RK, AJH, AL, SR, CS, MT, ET, and WTS contributed to the design of the AirCore and subsampling equipment and the various balloon campaigns with ECLE, ESD, and ET also involved in the halocarbon measurements and data analysis. CAMB and DEO were responsible for CARIBIC, and TR was responsible for the Geophysika aircraft measurement, sampling equipment, and related discussions. SAM provided NOAA northern hemispheric time series and useful respective insights, and JUG and FP led the modelling analysis. All authors contributed to the writing process of the article and scientific discussions surrounding it.

Competing interests. The authors declare that they have no conflict of interest.

Acknowledgements. This work was funded by the ERC project EXC3ITE and the UK Natural Environment Research Council. David E. Oram also received support from the National Centre for Atmospheric Science. We gratefully acknowledge the computing time for the CLaMS simulations granted on the supercomputer JURECA at Jülich Supercomputing Centre (JSC) under the VSR project ID JICG11. We thank all who helped with the balloon launches in Finland and the UK, the numerous NOAA station personnel and site scientists for sample flask collection and measurement, and Michel Bolder for collecting the Geophysika air samples; we also acknowledge the work of the Geophysika aircraft team. Related funding came from the European Space Agency (ESA, PremierEx and FRM4GHG projects), Forschungszentrum Jülich, the European Commission (FP7 projects RECONCILE, StratoClim, and H2020 project RINGO). We further thank Paul Konopka for carrying out some of the CLaMS simulations used here, Jörn Ungermann for help with code translations, and Rolf Müller for useful discussions.

Financial support. This research has been supported by the European Research Council (grant no. EXC3ITE (678904)), the Natural Environment Research Council (grant nos. NE/I021918/1 and NE/L002582/1), the Helmholtz Association (grant no. VHNG-1128), the European Commission (grant nos. StratoClim603557-FP7-ENV-2013-two-stage and RECONCILE-226365FP7-ENV-2008-1), and the Dutch Science Foundation (NWO) (grant no. 865.07.001).

The article processing charges for this open-access 
publication were covered by a Research

Centre of the Helmholtz Association.

Review statement. This paper was edited by Peter Haynes and reviewed by two anonymous referees.

\section{References}

Bönisch, H., Engel, A., Birner, Th., Hoor, P., Tarasick, D. W., and Ray, E. A.: On the structural changes in the Brewer-Dobson circulation after 2000, Atmos. Chem. Phys., 11, 3937-3948, https://doi.org/10.5194/acp-11-3937-2011, 2011.

Brenninkmeijer, C. A. M., Crutzen, P., Boumard, F., Dauer, T., Dix, B., Ebinghaus, R., Filippi, D., Fischer, H., Franke, H., Frieß, U., Heintzenberg, J., Helleis, F., Hermann, M., Kock, H. H., Koeppel, C., Lelieveld, J., Leuenberger, M., Martinsson, B. G., Miemczyk, S., Moret, H. P., Nguyen, H. N., Nyfeler, P., Oram, D., O’Sullivan, D., Penkett, S., Platt, U., Pupek, M., Ramonet, M., Randa, B., Reichelt, M., Rhee, T. S., Rohwer, J., Rosenfeld, K., Scharffe, D., Schlager, H., Schumann, U., Slemr, F., Sprung, D., Stock, P., Thaler, R., Valentino, F., van Velthoven, P.,Waibel, A., Wandel, A., Waschitschek, K., Wiedensohler, A., Xueref-Remy, I., Zahn, A., Zech, U., and Ziereis, H.: Civil Aircraft for the regular investigation of the atmosphere based on an instrumented container: The new CARIBIC system, Atmos. Chem. Phys., 7, 4953-4976, https://doi.org/10.5194/acp-7-4953-2007, 2007.

Dee, D. P., Uppala, S. M., Simmons, A. J., Berrisford, P., Poli, P., Kobayashi, S., Andrae, U., Balmaseda, M. A., Balsamo, G., Bauer, P., Bechtold, P., Beljaars, A. C. M., van de Berg, L., Bidlot, J., Bormann, N., Delsol, C., Dragani, R., Fuentes, M., Geer, A. J., Haimberger, L., Healy, S. B., Hersbach, H., Hólm, E. V., Isaksen, L., Kållberg, P., Köhler, M., Matricardi, M., McNally, A. P., Monge-Sanz, B. M., Morcrette, J.-J., Park, B.-K., Peubey, C., de Rosnay, P., Tavolato, C., Thépaut, J.-N., and Vitart, F.: The ERA-Interim reanalysis: configuration and performance of the data assimilation system, Q. J. Roy. Meteor. Soc., 137, 553-597, https://doi.org/10.1002/qj.828, 2011.

Douglass, A. R., Stolarski, R. S., Schoeberl, M. R., Jackman, C. H., Gupta, M. L., Newman, P. A., Nielsen, J. E., and Fleming, E. L.: Relationship of loss, mean age of air and the distribution of CFCs to stratospheric circulation and implications for atmospheric lifetimes, J. Geophys. Res., 113, D14309, https://doi.org/10.1029/2007JD009575, 2008.

Engel, A., Mobius, T., Bönisch, H., Schmidt, U., Heinz, R., Levin, I., Atlas, E., Aoki, S., Nakazawa, T., Sugawara, S., Moore, F., Hurst, D., Elkins, J., Schauffler, S., Andrews, A., and Boering, K.: Age of stratospheric air unchanged within uncertainties over the past 30 years, Nat. Geosci., 2, 28-31, https://doi.org/10.1038/Ngeo388, 2009.

Engel, A., Bönisch, H., Ullrich, M., Sitals, R., Membrive, O., Danis, F., and Crevoisier, C.: Mean age of stratospheric air derived from AirCore observations, Atmos. Chem. Phys., 17, 68256838, https://doi.org/10.5194/acp-17-6825-2017, 2017.

Gelaro, R., McCarty, W., Suárez, M. J., Todling, R., Molod, A., Takacs, L., Randles, C. A., Darmenov, A., Bosilovich, M. G., Reichle, R., Wargan, K., Coy, L., Cullather, R., Draper, C., Akella, S., Buchard, V., Conaty, A., da Silva, A. M., Gu, W., Kim, G.-
K., Koster, R., Lucchesi, R., Merkova, D., Nielsen, J. E., Partyka, G., Pawson, S., Putman,W., Rienecker, M., Schubert, S. D., Sienkiewicz, M., and Zhao, B.: The Modern-Era Retrospective Analysis for Research and Applications, Version 2 (MERRA2), J. Clim., 30, 5419-5454, https://doi.org/10.1175/JCLI-D-160758.1, 2017.

Harrison, J. J., Chipperfield, M. P., Hossaini, R., Boone, C. D., Dhomse, S., Feng, W., and Bernath, P. F.: Phosgene in the upper troposphere and lower stratosphere: A marker for product gas injection due to chlorine-containing very short lived Substances, Geophys. Res. Lett., 46, 1032-1039, https://doi.org/10.1029/2018GL079784, 2019.

Höpfner, M., Ungermann, J., Borrmann, S., Wagner, R., Spang, R., Riese, M., Stiller, G., Appel, O., Batenburg, A. M., Bucci, S.,Cairo, F., Dragoneas, A., Friedl-Vallon, F., Hünig, A., Johansson, S., Krasauskas, L., Legras, B., Leisner, T., Mahnke, C., Möhler, O.,Molleker, S., Müller, R., Neubert, T., Orphal, J., Preusse, P., Rex, M., Saathoff, H., Stroh, F., Weigel, R., and Wohltmann, I.: Ammonium nitrate particles formed in upper troposphere from ground ammonia sources during Asian monsoons, Nat. Geosci., 12, 608-612, https://doi.org/10.1038/s41561-0190385-8, 2019.

Karion, A., Sweeney, C., Tans, P., and Newberger, T.: AirCore: An Innovative Atmospheric Sampling System, J. Atmos. Ocean. Tech., 27, 1839-1853, https://doi.org/10.1175/2010JTECHA1448.1, 2010.

Kida, H.: General-Circulation of Air Parcels and Transport Characteristics Derived from a Hemispheric Gcm, 2. Very Long-Term Motions of Air Parcels in the Troposphere and Stratosphere, J. Meteorol. Soc. Jpn. 61, 510-523, 1983.

Kloss, C., Newland, M. J., Oram, D. E., Fraser, P. J., Brenninkmeijer, C. A. M., Röckmann, T., and Laube, J. C.: Atmospheric abundances, trends and emissions of CFC-216ba, CFC-216ca and HCFC-225ca, Atmosphere, 5, 420-434, 2014.

Kobayashi, S., Ota, Y., Harada, Y., Ebita, A., Moriya, M., Onoda, H., Onogi, K., Kamahori, H., Kobayashi, C., Endo, H., Miyaoka, K., and Takahashi, K.: The JRA-55 Reanalysis: General Specifications and Basic Characteristics, J. Meteorol. Soc. Jpn., 93, 5-48, https://doi.org/10.2151/jmsj.2015-001, 2015.

Laube, J. C., Martinerie, P., Witrant, E., Blunier, T., Schwander, J., Brenninkmeijer, C. A. M., Schuck, T. J., Bolder, M., Röckmann, T., van der Veen, C., Bönisch, H., Engel, A., Mills, G. P., Newland, M. J., Oram, D. E., Reeves, C. E., and Sturges, W. T.: Accelerating growth of HFC-227ea (1,1,1,2,3,3,3-heptafluoropropane) in the atmosphere, Atmos. Chem. Phys., 10, 5903-5910, https://doi.org/10.5194/acp-10-5903-2010, 2010.

Laube, J. C., Hogan, C., Newland, M. J., Mani, F. S., Fraser, P. J., Brenninkmeijer, C. A. M., Martinerie, P., Oram, D. E., Röckmann, T., Schwander, J., Witrant, E., Mills, G. P., Reeves, C. E., and Sturges,W. T.: Distributions, long term trends and emissions of four perfluorocarbons in remote parts of the atmosphere and firn air, Atmos. Chem. Phys., 12, 4081-4090, https://doi.org/10.5194/acp-12-4081-2012, 2012.

Laube, J. C., Keil, A., Bönisch, H., Engel, A., Röckmann, T., Volk, C. M., and Sturges, W. T.: Observation-based assessment of stratospheric fractional release, lifetimes, and ozone depletion potentials of ten important source gases, Atmos. Chem. Phys., 13, 2779-2791, https://doi.org/10.5194/acp-132779-2013, 2013. 
Leedham Elvidge, E. C., Oram, D. E., Laube, J. C., Baker, A. K., Montzka, S. A., Humphrey, S., O'Sullivan, D. A., and Brenninkmeijer, C. A. M.: Increasing concentrations of dichloromethane, $\mathrm{CH}_{2} \mathrm{Cl}_{2}$, inferred from CARIBIC air samples collected 1998-2012, Atmos. Chem. Phys., 15, 1939-1958, https://doi.org/10.5194/acp-15-1939-2015, 2015.

Leedham Elvidge, E., Bönisch, H., Brenninkmeijer, C. A. M., Engel, A., Fraser, P. J., Gallacher, E., Langenfelds, R., Mühle, J., Oram,20D. E., Ray, E. A., Ridley, A. R., Röckmann, T., Sturges, W. T., Weiss, R. F., and Laube, J. C.: Evaluation of stratospheric age of air from $\mathrm{CF}_{4}, \mathrm{C}_{2} \mathrm{~F}_{6}, \mathrm{C}_{3} \mathrm{~F}_{8}, \mathrm{CHF}_{3}$, HFC-125, HFC-227ea and $\mathrm{SF}_{6}$; implications for the calculations of halocarbon lifetimes, fractional releasefactors and ozone depletion potentials, Atmos. Chem. Phys., 18, 3369-3385, https://doi.org/10.5194/acp-18-3369-2018, 2018.

McKenna, D. S., Konopka, P., Grooß, J.-U., Günther, G., Müller, R., Spang, R., Offermann, D., and Orsolini, Y.: A new Chemical Lagrangian Model of the Stratosphere (CLaMS): 1. Formulation of advection and mixing, J. Geophys. Res., 107, 4309, https://doi.org/10.1029/2000JD000114, 2002.

Membrive, O., Crevoisier, C., Sweeney, C., Danis, F., Hertzog, A., Engel, A., Bönisch, H., and Picon, L.: AirCore-HR: a highresolution column sampling to enhance the vertical description of $\mathrm{CH}_{4}$ and $\mathrm{CO}_{2}$, Atmos. Meas. Tech., 10, 2163-2181, https://doi.org/10.5194/amt-10-2163-2017, 2017.

Montzka, S. A., Dutton, R., Yu, P., Ray, E., Portmann, R. W., Daniel, J. S., Kuijpers, L., Hall, B. D., Mondeel, D., Siso, C., Nance, D. J., Rigby, M., Manning, A. J., Hu, L., Moore, F., Miller, B. R., and Elkins, J. W.: A persistent and unexpected increase in global emissions of ozone-depleting CFC-11, Nature, 557, 413417, https://doi.org/10.1038/s41586-018-0106-2, 2018.

Mrozek, D. J., van der Veen, C., Hofmann, M. E. G., Chen, H., Kivi,R., Heikkinen, P., and Röckmann, T.: Stratospheric Air Subsampler (SAS) and its application to analysis of $\Delta^{17} \mathrm{O}\left(\mathrm{CO}_{2}\right)$ from small air samples collected with an AirCore, Atmos. Meas. Tech., 9, 5607-5620, https://doi.org/10.5194/amt-9-5607-2016, 2016.

Oram, D. E., Ashfold, M. J., Laube, J. C., Gooch, L. J., Humphrey, S., Sturges, W. T., Leedham-Elvidge, E., Forster, G. L., Harris, N. R. P., Mead, M. I., Samah, A. A., Phang, S. M., Ou-Yang, C.-F., Lin, N.-H., Wang, J.-L., Baker, A. K., Brenninkmeijer, C. A. M., and Sherry, D.: A growing threat to the ozone layer from short-lived anthropogenic chlorocarbons, Atmos. Chem. Phys., 17, 11929-11941, https://doi.org/10.5194/acp-17-119292017, 2017.

Paul, D., Chen, H., Been, H. A., Kivi, R., and Meijer, H. A. J.: Radiocarbon analysis of stratospheric $\mathrm{CO}_{2}$ retrieved from AirCore sampling, Atmos. Meas. Tech., 9, 4997-5006, https://doi.org/10.5194/amt-9-4997-2016, 2016.

Ploeger, F., Konopka, P., Müller, R., Fueglistaler, S., Schmidt, T., Manners, J., Grooss, J.-U., Günther, G., de Forster, P. M., and Riese, M.: Horizontal transport affecting trace gas seasonality in the Tropical Tropopause Layer (TTL), J. Geophys. Res., 117, D09303, https://doi.org/10.1029/2011JD017267, 2012.

Ploeger, F., Legras, B., Charlesworth, E., Yan, X., Diallo, M., Konopka, P., Birner, T., Tao, M., Engel, A., and Riese, M.: How robust are stratospheric age of air trends from different reanalyses?, Atmos. Chem. Phys., 19, 6085-6105, https://doi.org/10.5194/acp-19-6085-2019, 2019.
Polvani, L. M., Abalos, M., Garcia, R., Kinnison, D., and Randel, W. J.: Significant weakening of Brewer-Dobson circulation trends over the 21 st century as a consequence of the Montreal Protocol, Geophys. Res. Lett., 45, 401-409, 2018.

Pommrich, R., Müller, R., Grooß, J.-U., Konopka, P., Ploeger, F., Vogel, B., Tao, M., Hoppe, C. M., Günther, G., Spelten, N., Hoffmann,L., Pumphrey, H.-C., Viciani, S., D’Amato, F., Volk, C. M., Hoor, P., Schlager, H., and Riese, M.: Tropical troposphere to stratosphere transport of carbon monoxide and long-lived trace species in the Chemical Lagrangian Model of the Stratosphere (CLaMS), Geosci. Model Dev., 7, 2895-2916, https://doi.org/10.5194/gmd-7-2895-2014, 2014.

Randel, W. J., Park, M., Emmons, L., Kinnison, D., Bernath, P., Walker, K. A., Boone, C., and Pumphrey, H.: Asian Monsoon Transport of Pollution to the Stratosphere, Science, 328, 611613, https://doi.org/10.1126/science.1182274, 2010.

Ray, E. A., Moore, F. L., Elkins, J. W., Rosenlof, K., Laube, J., Röckmann, T., Marsh, D. R., and Andrews, A. E.: Quantification of the SF6 Lifetime Based on Mesospheric Loss Measured in the Stratospheric Polar Vortex, J. Geophys. Res.-Atmos., 122, 46264638, https://doi.org/10.1002/2016JD026198, 2017.

Ray, E. A., Portmann, R. W., Yu, P., Daniel, J., Montzka, S. A., Dutton, G. S., Hall, B. D., Moore, F. L., and Rosenlof, K. H.: The influence of the stratospheric Quasi-Biennial Oscillation on trace gas levels at the Earth's surface, Nat. Geosci. 13, 22-27, https://doi.org/10.1038/s41561-019-0507-3, 2020.

Rigby, M., Park, S., Saito, T., Western, L. M., Redington, A. L., Fang, X., Henne, S., Manning, A. J., Prinn, R. G., Dutton, G. S., Fraser, P. J., Ganesan, A. L., Hall, B. D., Harth, C. M., Kim, J., Kim, K.-R., Krummel, P. B., Lee, T., Li, S., Liang, Q., Lunt, M. F., Montzka, S. A., Mühle, J., O’Doherty, S., Park, M.-K., Reimann, S., Salameh, P. K., Simmonds, P., Tunnicliffe, R. L., Weiss, R. F., Yokouchi, Y., and Young, D.: Increase in CFC11 emissions from eastern China based on atmospheric observations, Nature, 569, 546-550, https://doi.org/10.1038/s41586019-1193-4, 2019.

Santee, M. L., Livesey, N. J., Manney, G. L., Lambert, A., and Read,W. G.: Methyl chloride from the Aura Microwave Limb Sounder:First global climatology and assessment of variability in the up-per troposphere and stratosphere, J. Geophys. Res.-Atmos., 118, 13532-13560, https://doi.org/10.1002/2013JD020235, 2013.

Schauffler, S. M., Atlas, E. L., Donnelly, S. G., Andrews, A., Montzka, S. A., Elkins, J. W., Hurst, D. F., Romashkin, P. A., Dutton, G. S., and Stroud, V.: Chlorine budget and partitioning during SOLVE, J. Geophys. Res., 108, 4173, https://doi.org/10.1029/2001JD002040, 2003.

Schmidt, U. and Khedim, A.: In situ measurements of carbon dioxide in the winter Arctic vortex and at midlatitudes: An indicator of the "age" of stratospheric air, Geophys. Res. Lett., 18, 763766, 1991.

Stiller, G. P., von Clarmann, T., Höpfner, M., Glatthor, N., Grabowski, U., Kellmann, S., Kleinert, A., Linden, A., Milz, M., Reddmann, T., Steck, T., Fischer, H., Funke, B., LópezPuertas, M., and Engel, A.: Global distribution of mean age of stratospheric air from MIPAS SF6 measurements, Atmos. Chem. Phys., 8, 677-695, https://doi.org/10.5194/acp-8-6772008, 2008. 
Stiller, G. P., von Clarmann, T., Haenel, F., Funke, B., Glatthor, N., Grabowski, U., Kellmann, S., Kiefer,M., Linden, A., Lossow, S., and Lóppez-Puertas, M.: Observed temporal evolution of global mean age of stratospheric air for the 2002 to 2010 period, Atmos. Chem. Phys., 12, 3311-3331, https://doi.org/10.5194/acp12-3311-2012, 2012.

Trudinger, C. M., Fraser, P. J., Etheridge, D. M., Sturges, W. T., Vollmer, M. K., Rigby, M., Martinerie, P., Mühle, J., Worton, D. R., Krummel, P. B., Steele, L. P., Miller, B. R., Laube, J., Mani, F. S., Rayner, P. J., Harth, C. M., Witrant, E., Blunier, T., Schwander, J., O'Doherty, S., and Battle, M.: Atmospheric abundance and global emissions of perfluorocarbons $\mathrm{CF}_{4}, \mathrm{C}_{2} \mathrm{~F}_{6}$, and $\mathrm{C}_{3} \mathrm{~F}_{8}$ since 1800 inferred from ice core, firn, air archive and in situ measurements, Atmos. Chem. Phys., 16, 11733-11754, https://doi.org/10.5194/acp-16-11733-2016, 2016.

Vogel, B., Müller, R., Günther, G., Spang, R., Hanumanthu, S., Li, D., Riese, M., and Stiller, G. P.: Lagrangian simulations of the transport of young air masses to the top of the Asian monsoon anticyclone and into the tropical pipe, Atmos. Chem. Phys., 19, 6007-6034, https://doi.org/10.5194/acp-19-6007-2019, 2019.

Volk, C. M., Elkins, J. W., Fahey, D. W., Dutton, G. S., Gilligan, J. M., Loewenstein, M., Podolske, J. R., Chan, K. R., and Gunson, M. R.: Evaluation of source gas lifetimes from stratospheric observations, J. Geophys. Res., 102, 25543-25564, https://doi.org/10.1029/97JD02215, 1997. von Hobe, M., Bekki, S., Borrmann, S., Cairo, F., D’Amato, F., Di Donfrancesco, G., Dörnbrack, A., Ebersoldt, A., Ebert, M., Emde, C., Engel, I., Ern, M., Frey, W., Genco, S., Griessbach, S., Grooß, J.-U., Gulde, T., Günther, G., Hösen, E., Hoffmann, L., Homonnai, V., Hoyle, C. R., Isaksen, I. S. A., Jackson, D. R., Jánosi, I. M., Jones, R. L., Kandler, K., Kalicinsky, C., Keil, A., Khaykin, S. M., Khosrawi, F., Kivi, R., Kuttippurath, J., Laube, J. C., Lefèvre, F., Lehmann, R., Ludmann, S., Luo, B. P., Marchand, M., Meyer, J., Mitev, V., Molleker, S., Müller, R., Oelhaf, H., Olschewski, F., Orsolini, Y., Peter, T., Pfeilsticker, K., Piesch, C., Pitts, M. C., Poole, L. R., Pope, F. D., Ravegnani, F., Rex, M., Riese, M., Röckmann, T., Rognerud, B., Roiger, A., Rolf, C., Santee, M. L., Scheibe, M., Schiller, C., Schlager, H., Siciliani de Cumis, M., Sitnikov, N., Søvde, O. A., Spang, R., Spelten, N., Stordal, F., Suminska-Ebersoldt, O., Ulanovski, A., Ungermann, J., Viciani, S., Volk, C. M., vom Scheidt, M., von der Gathen, P., Walker, K., Wegner, T., Weigel, R., Weinbruch, S., Wetzel, G., Wienhold, F. G., Wohltmann, I., Woiwode, W., Young, I. A. K., Yushkov, V., Zobrist, B., and Stroh, F.: Reconciliation of essential process parameters for an enhanced predictability of Arctic stratospheric ozone loss and its climate interactions (RECONCILE): activities and results, Atmos. Chem. Phys., 13, 92339268, https://doi.org/10.5194/acp-13-9233-2013, 2013. 